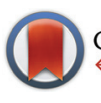

CrossMark

Cite this: Polym. Chem., 2016, 7, 3034

Received 18th March 2016, Accepted 5th April 2016

DOI: $10.1039 /$ c6py00483k

www.rsc.org/polymers

\title{
Direct functionalization of poly(vinyl chloride) by photo-mediated ATRP without a deoxygenation procedure $\uparrow$
}

\author{
Zhong Huang, ${ }^{a}$ Chun Feng, ${ }^{* a}$ Hao Guo ${ }^{b}$ and Xiaoyu Huang ${ }^{* a}$
}

\begin{abstract}
A facile strategy of Ir-catalyzed visible light mediated atom transfer radical polymerization (ATRP) was reported toward direct modification of commercial poly(vinyl chloride) (PVC) by graft polymerization of methacrylate monomers, such as methyl methacrylate (MMA), pentafluorophenyl methacrylate (PFMA), and oligo(ethylene glycol) methyl ether methacrylate (OEGMA). This approach also allows (co)polymerization of acidic monomers of methacrylic acid (MAA), which is usually incompatible with conventional ATRP. In this approach, the structural defects of allyl chloride and tertiary chloride groups of PVC, along with some of the secondary chlorides of vinyl chloride repeated units, were activated to serve as initiating sites for photo-mediated ATRP by using $\operatorname{Ir}(\mathrm{ppy})_{3}$ as a photo-redox catalyst under low intensity blue LED light strips (10 W, 460-470 nm) in DMF, probably preserving secondary C-Cl bonds of VC repeated units. The polymerization can be effectively tuned between "activation" and "deactivation" states by alternating light "ON" and "OFF" with the maintenance of a linear increase in molecular weight with conversion and first order kinetics. Most importantly, this kind of polymerization shows great tolerance with oxygen, which can proceed in a closed vessel with a controlled/living manner without a deoxygenation procedure. Additionally, this strategy can be employed for the surface functionalization of commercial PVC sheets by surface-initiated ATRP of methacrylate monomers, i.e. PFMA and OEGMA, without prerequisite of functionality transformation and deoxygenation procedures. The surface water contact angles of the PVC sheet changed from $74^{\circ}$ to $11^{\circ}$ and above $92^{\circ}$ after surface functionalization with POEGMA and PPFMA, respectively. Due to the spatially controlled ability of this strategy, the selective regulation in location and density of the surface functionalization of PVC, that is, surface patterning can be realized by modulating the dosage of light.
\end{abstract}

\section{Introduction}

Poly(vinyl chloride) (PVC), the second most produced plastic polymer after polyethylene, has been one of the most important polymers in our daily life for more than 80 years with broad applications from engineering materials to medical devices. ${ }^{1-3}$ Besides the intrinsic properties of PVC itself, the performance of PVC-based materials are sometimes highly related to their surface properties, and thus, the surface of PVC-based materials are often modified so as to make them

\footnotetext{
${ }^{a}$ Key Laboratory of Synthetic and Self-Assembly Chemistry for Organic Functional Molecules, Shanghai Institute of Organic Chemistry, Chinese Academy of Sciences, 345 Lingling Road, Shanghai 200032, People's Republic of China.

E-mail: cfeng@mail.sioc.ac.cn,xyhuang@mail.sioc.ac.cn;

Fax: +86-21-64166128, +86-21-64166128; Tel: +86-21-54925606, +86-21-54925310

${ }^{b}$ Department of Chemistry, Fudan University, 220 Handan Road, Shanghai 200433, People's Republic of China

$\dagger$ Electronic supplementary information (ESI) available. See DOI: 10.1039/ c6py00483k
}

meet some specific requirements including adhesiveness, chemical resistance, physical corrosion, hydrophilicity, hydrophobicity, lubricity, anti-fouling, and anti-microbial properties and so on, for diverse applications. ${ }^{4}$ Therefore, a variety of strategies have been employed for the surface functionalization of PVC-based materials such as chemical reactions, plasmaion beam, and electric discharge treatments. ${ }^{4-8}$ Since some special instruments are prerequisites for the plasma-ion beam and electric discharge treatment approaches, chemical reactions are considered to be a more facile approach for the surface modification of PVC-based materials. ${ }^{4}$ Due to the simplicity of the chemical structure of PVC, it is not easy to introduce functionalities into PVC efficiently.

Even so, some chemical reactions have been developed for the functionalization of PVC. For example, Bakker et al. reported the functionalization of PVC by the combination of a substitution reaction of the C-Cl groups of PVC with $\mathrm{NaN}_{3}$ and a Huisgen cycloaddition reaction between azide and alkyne groups. ${ }^{9} \mathrm{Su}$ et al. also employed a substitution reaction of the 
$\mathrm{C}-\mathrm{Cl}$ groups of PVC with amine-based functionalities to modify PVC. ${ }^{10}$ Although functional groups or polymers can be installed into PVC by employing these chemical reactions, all of them require at least two chemical reaction steps to introduce specific functionalities and polymers. Possibly inspired by Kennedy's work on cationic graft copolymerization from structural defects of the allyl chloride and tertiary chloride groups of commercial PVC, ${ }^{11}$ Percec et al. reported that these structural defects could serve as initiating sites for graft copolymerization of conventional vinylic monomers by ATRP using a Cu-based catalytic system, including methyl methacrylate, styrene, acrylonitrile and so on. ${ }^{12-15}$ Since PVC can be easily and efficiently functionalized without additional modification to introduce initiating groups by the versatile and powerful tool of ATRP with merits of ease in conducting, good tolerance to functional groups, excellent tunability in the composition, molecular weight, and architecture of the polymer synthesized, this strategy was widely employed for the modification of PVC to prepare PVC-based solar cells, nanocomposites for $\mathrm{CO}_{2}$ capture, and beads for metal extraction. ${ }^{16-19}$ Although this method shows great potential in direct functionalization of PVC and surface modification of PVC-based materials, large amounts of Cu-based catalyst, roughly in equivalent concentration to the apparent $\mathrm{R}-\mathrm{Cl}$ initiating groups, and a relatively high polymerization temperature $\left(\geq 60{ }^{\circ} \mathrm{C}\right)$ were needed to obtain better control over the polymerization process.

Recently, photo-chemically mediated ATRP has attracted increasing attention because it will not only provide us opportunities in spatial and temporal control over the ATRP process without the loss of merits of conventional ATRP, but will make the ATRP process more eco-friendly with a significant decrease in the use of metal-based catalyst, to the level of ppm, and a low polymerization temperature (ambient temperature). ${ }^{20-32}$ Considering the broad applications of PVC and the importance of the surface properties of PVC-based materials in their specific utilities, it is necessary to expand the photo-chemically mediated ATRP into functionalization of PVC. However, reports on the functionalization of PVC by photo-chemically mediated ATRP are rare. ${ }^{33}$

Recently, Hawker et al. developed photo-chemically mediated ATRP of methyl methacrylate (MMA) and methyl acrylate (MA) by employing Ir-based photo-redox catalysts. ${ }^{29-32}$ They proposed that the excited photocatalyst activated after absorption of visible light with a certain wavelength could reduce an alkyl bromide initiator to afford the desired alkyl radicals for initiating polymerization. The amount of catalyst could be cut to as low as only ppm levels with excellent control over the polymerization and good tolerance to carboxyl functionality. These advantages motivate us to expand this methodology into the modification of PVC and surfaces of PVC-based materials. Herein, we demonstrated for the first time the applicability of photo-chemically mediated ATRP to functionalize commercial PVC by directly employing structural defects of PVC as initiating sites for polymerization without additional reactions to introduce initiating sites for polymerization. In the first part of this article, we examined the catalytic behaviors of $\operatorname{Ir}(\mathrm{ppy})_{3}$ and $\mathrm{Ru}(\mathrm{bpy})_{3}$ for graft polymerization of MMA from PVC in DMF under blue LED irradiation $\left(\lambda_{\max }=\right.$ $460 \mathrm{~nm}, 10 \mathrm{~W})$. Subsequently, we investigated the photomediated ATRP of pentafluoro-phenyl methacrylate (PFMA), oligo(ethylene glycol) methyl ether methacrylate (OEGMA), and methacrylic acid (MAA) and its oxygen tolerance. Finally, we utilized this approach without tedious deoxygenation procedures to functionalize the surface of commercial PVC sheets and exploited the spatially controlled capacity of the polymerization on the surface modification of PVC sheets.

\section{Experimental section}

\section{Materials}

Poly(vinyl chloride) powder (PVC, $M_{\mathrm{n}}=22000 \mathrm{~g} \mathrm{~mol}^{-1}, M_{\mathrm{w}}=$ $43000 \mathrm{~g} \mathrm{~mol}^{-1}$ ), methyl methacrylate (MMA, 99\%), methacrylic acid (MAA), and oligo(ethylene glycol) methyl ether methacrylate (OEGMA, $M_{\mathrm{n}}=500 \mathrm{~g} \mathrm{~mol}^{-1}$ ) were purchased from Aldrich. $\mathrm{Ru}(\mathrm{bpy})_{3} \mathrm{Cl}_{2}$ (99\%), $\operatorname{Ir}(\mathrm{ppy})_{3}$ (99\%), $N, N$-dimethylformamide (DMF, >99.5\%), dimethyl sulfoxide (DMSO, >99\%), and diphenyl ether (99\%) were purchased from TCI. The PVC sheet was purchased from Jingdong Market and used as received. Deinhibition of the monomer was performed by percolating over a column of basic alumina. DMF and DMSO were distilled prior to use. Pentafluorophenyl methacrylate (PFMA) was prepared according to previous literature. ${ }^{34}$

\section{Instrumentation}

Relative molecular weights and molecular weight distributions were measured using a conventional gel permeation chromatography (GPC) system equipped with a Waters 1515 Isocratic HPLC pump, a Waters 2414 refractive index detector, a Waters 2487 dual $\lambda$ absorbance detector, and a set of Waters Styragel columns (HR3 (500-30 000), HR4 (5000-600 000), and HR5 (50 000-4 000000$), 7.8 \times 300 \mathrm{~mm}$, particle size $5 \mu \mathrm{m})$. GPC measurements were carried out at $35^{\circ} \mathrm{C}$ using THF and $\mathrm{LiBr}-$ added DMF $([\mathrm{LiBr}]=50 \mathrm{mM})$ as eluents with a flow rate of $1.0 \mathrm{~mL} \mathrm{~min}^{-1}$. The system was calibrated with linear polystyrene standards. The absolute molecular weight of PVC $3^{\text {rd }}$ fraction was determined using GPC equipped with a multiangle light scattering detector (GPC/MALS), THF was used as the eluent with a flow rate of $1.0 \mathrm{~mL} \mathrm{~min}^{-1}$, detectors: Wyatt Optilab rEX refractive index detector and Wyatt DAWN HELEOS 18-angle light scattering detector with a $50 \mathrm{~mW}$ solidstate laser operating at $658 \mathrm{~nm} .{ }^{1} \mathrm{H}$ NMR (500 MHz) analyses were performed on a Bruker Avance 500 spectrometer in $\mathrm{CDCl}_{3}$ and DMSO- $d_{6}$, TMS was used as an internal standard. X-ray photoelectron spectroscopy (XPS) was recorded on a PHI 5000c ESCA photoelectron spectrometer.

\section{Fractional precipitation of commercial PVC}

Fractional precipitation of $\mathrm{PVC}^{13}$ was carried out several times for the commercial PVC sample $\left(M_{\mathrm{n}}=22000 \mathrm{~g} \mathrm{~mol}{ }^{-1}, M_{\mathrm{w}}=\right.$ $43000 \mathrm{~g} \mathrm{~mol}^{-1}$, Aldrich). $10 \mathrm{~g}$ of PVC was slowly added to a round flask containing $1 \mathrm{~L}$ of $\mathrm{CH}_{2} \mathrm{Cl}_{2}$ and stirred overnight to 
allow the complete solubilization of the polymer. Methanol $(220 \mathrm{~mL})$ was added to the solution to precipitate the first PVC fraction with the highest molecular weight. This fraction was centrifuged, the upper solution in the centrifuge tubes was decanted and the fraction of PVC was solubilized in THF and precipitated in methanol. This procedure was repeated for the remaining solution to obtain different fractions. After adding the second $(80 \mathrm{~mL})$ and third $(150 \mathrm{~mL})$ batches of methanol, we obtained the third fraction of PVC $\left(M_{\mathrm{n}, \mathrm{GPC} / \mathrm{MALS}}=\right.$ $12850 \mathrm{~g} \mathrm{~mol}^{-1}, M_{\mathrm{w}} / M_{\mathrm{n}}=1.14$ ) with a total yield of $12 \%$ for further reactions.

\section{Preparation of PVC- $g$-PMMA, PVC- $g$-PPFMA, and PVC-g-POEGMA}

In a typical procedure, a reaction solution consisting of DMF (3 mL), PVC $\left(M_{\mathrm{n}, \mathrm{GPC} / \mathrm{MALS}}=12850 \mathrm{~g} \mathrm{~mol}^{-1}, M_{\mathrm{w}} / M_{\mathrm{n}}=1.14\right.$, $0.21 \mathrm{~g})$, MMA (0.80 g, $8 \mathrm{mmol})$, and $\operatorname{Ir}(\mathrm{ppy})_{3}(0.026 \mathrm{mg}, 4.0 \times$ $10^{-5} \mathrm{mmol}$ ) was first prepared in a glass vial sealed with a rubber septum. The mixture was deoxygenated by 3 cycles of freezing-pumping-thawing and irradiated under blue LED light strips (10 W, 460-470 nm, see Fig. S1 in ESI $\dagger$ ) at room temperature. The polymerization lasted $24 \mathrm{~h}$ and the final mixture was purified via precipitation in methanol 3 times. $M_{\mathrm{n}, \mathrm{NMR}}=24750 \mathrm{~g} \mathrm{~mol}{ }^{-1}, M_{\mathrm{w}} / M_{\mathrm{n}}=1.31 .{ }^{1} \mathrm{H} \mathrm{NMR}\left(\mathrm{CDCl}_{3}\right)$ : $\delta$ (ppm): 0.84, $1.04\left(3 \mathrm{H}, \mathrm{CH}_{2} \mathrm{C}\left(\mathrm{CH}_{3}\right)\right), 2.15\left(2 \mathrm{H}, \mathrm{CH}_{2} \mathrm{C}\left(\mathrm{CH}_{3}\right)\right)$, $2.40\left(2 \mathrm{H}, \mathrm{CH}_{2} \mathrm{CHCl}\right), 3.60\left(3 \mathrm{H}, \mathrm{OCH}_{3}\right), 4.66\left(1 \mathrm{H}, \mathrm{CH}_{2} \mathrm{CHCl}\right)$.

A reaction solution consisting of DMF (3 $\mathrm{mL})$, PVC $\left(M_{\mathrm{n}, \mathrm{GPC} / \mathrm{MALS}}=12850 \mathrm{~g} \mathrm{~mol}{ }^{-1}, M_{\mathrm{w}} / M_{\mathrm{n}}=1.14,0.21 \mathrm{~g}\right)$, PFMA $(2.02 \mathrm{~g}, 8 \mathrm{mmol})$, and $\operatorname{Ir}(\mathrm{ppy})_{3}\left(0.026 \mathrm{mg}, 4.0 \times 10^{-5} \mathrm{mmol}\right)$ was first prepared in a glass vial sealed with a rubber septum. The mixture was deoxygenated by 3 cycles of freezingpumping-thawing and irradiated under blue LED light strips (10 W, 460-470 $\mathrm{nm}$ ) at room temperature. The polymerization lasted $20 \mathrm{~h}$ and the final mixture was purified via precipitation in methanol 3 times. $M_{\mathrm{n}, \mathrm{NMR}}=44240 \mathrm{~g} \mathrm{~mol}{ }^{-1}, M_{\mathrm{w}} / M_{\mathrm{n}}=1.29$. ${ }^{1} \mathrm{H}$ NMR $\left(\mathrm{CDCl}_{3}\right): \delta$ (ppm): $1.42\left(3 \mathrm{H}, \mathrm{CH}_{2} \mathrm{C}\left(\mathrm{CH}_{3}\right)\right), \quad 2.15$ $\left(2 \mathrm{H}, \mathrm{CH}_{2} \mathrm{C}\left(\mathrm{CH}_{3}\right)\right), 2.40\left(2 \mathrm{H}, \mathrm{CH}_{2} \mathrm{CHCl}\right), 4.66\left(1 \mathrm{H}, \mathrm{CH}_{2} \mathrm{CHCl}\right)$.

A reaction solution consisting of DMF (3 $\mathrm{mL})$, PVC $\left(M_{\mathrm{n}, \mathrm{GPC} / \mathrm{MALS}}=12850 \mathrm{~g} \mathrm{~mol}^{-1}, M_{\mathrm{w}} / M_{\mathrm{n}}=1.14,0.21 \mathrm{~g}\right)$, OEGMA $(4.00 \mathrm{~g}, 8 \mathrm{mmol})$, and $\operatorname{Ir}(\mathrm{ppy})_{3}\left(0.052 \mathrm{mg}, 8.0 \times 10^{-5} \mathrm{mmol}\right)$ was first prepared in a glass vial sealed with a rubber septum. The mixture was deoxygenated by 3 cycles of freezingpumping-thawing and irradiated under blue LED light strips (10 W, 460-470 nm) at room temperature. The polymerization lasted $12 \mathrm{~h}$ and the final mixture was purified via precipitation in cold diethyl ether 3 times. $M_{\mathrm{n}, \mathrm{NMR}}=77470 \mathrm{~g} \cdot \mathrm{mol}^{-1}, M_{\mathrm{w}} /$ $M_{\mathrm{n}}=1.28 .{ }^{1} \mathrm{H} \mathrm{NMR}\left(\mathrm{CDCl}_{3}\right): \delta(\mathrm{ppm}): 0.84,0.97\left(3 \mathrm{H}, \mathrm{CH}_{2} \mathrm{C}\right.$ $\left.\left(\mathrm{CH}_{3}\right)\right), 2.15\left(2 \mathrm{H}, \mathrm{CH}_{2} \mathrm{C}\left(\mathrm{CH}_{3}\right)\right), 2.40\left(2 \mathrm{H}, \mathrm{CH}_{2} \mathrm{CHCl}\right), 3.38(3 \mathrm{H}$, $\left.\mathrm{OCH}_{3}\right), 3.70\left(4 \mathrm{H}, \mathrm{OCH}_{2} \mathrm{CH}_{2}\right), 4.10\left(2 \mathrm{H}, \mathrm{CO}_{2} \mathrm{CH}_{2}\right), 4.66(1 \mathrm{H}$, $\left.\mathrm{CH}_{2} \mathrm{CHCl}\right)$.

\section{Preparation of PVC- $g$-PMMA and PVC- $g$-PPFMA in the presence of oxygen}

A reaction solution consisting of DMF (3 mL), PVC $\left(M_{\mathrm{n}, \mathrm{GPC} / \mathrm{MALS}}=12850 \mathrm{~g} \mathrm{~mol}{ }^{-1}, M_{\mathrm{w}} / M_{\mathrm{n}}=1.14,0.21 \mathrm{~g}\right)$, MMA $(0.80 \mathrm{~g}, 8 \mathrm{mmol})$, and $\operatorname{Ir}(\text { ppy })_{3}\left(0.26 \mathrm{mg}, 4.0 \times 10^{-4} \mathrm{mmol}\right)$ was first prepared in a glass vial sealed with a rubber septum. The mixture was irradiated under blue LED light strips $(10 \mathrm{~W}$, 460-470 nm) at room temperature without deoxygenation. The polymerization lasted $24 \mathrm{~h}$ and the final mixture was purified via precipitation in methanol 3 times. $M_{\mathrm{n}, \mathrm{NMR}}=$ $18200 \mathrm{~g} \mathrm{~mol}^{-1}, M_{\mathrm{w}} / M_{\mathrm{n}}=1.22$.

A reaction solution consisting of DMF (3 mL), PVC $\left(M_{\mathrm{n}, \mathrm{GPC} / \mathrm{MALS}}=12850 \mathrm{~g} \mathrm{~mol}^{-1}, M_{\mathrm{w}} / M_{\mathrm{n}}=1.14,0.21 \mathrm{~g}\right)$, PFMA $(2.02 \mathrm{~g}, 8 \mathrm{mmol})$, and $\operatorname{Ir}(\text { ppy })_{3}\left(0.26 \mathrm{mg}, 4.0 \times 10^{-4} \mathrm{mmol}\right)$ was first prepared in a glass vial sealed with a rubber septum. The mixture was irradiated under blue LED light strips $(10 \mathrm{~W}$, 460-470 nm) at room temperature without deoxygenation. The polymerization lasted $12 \mathrm{~h}$ and the final mixture was purified via precipitation in methanol 3 times. $M_{\mathrm{n}, \mathrm{NMR}}=51770 \mathrm{~g}$ $\mathrm{mol}^{-1}, M_{\mathrm{w}} / M_{\mathrm{n}}=1.39$.

\section{Preparation of PVC-g-(PMMA-co-PMAA)}

In a typical procedure, a reaction solution consisting of DMF (3 mL), PVC $\left(M_{\mathrm{n}, \mathrm{GPC} / \mathrm{MALS}}=12850 \mathrm{~g} \mathrm{~mol}{ }^{-1}, M_{\mathrm{w}} / M_{\mathrm{n}}=1.14\right.$, $0.21 \mathrm{~g})$, MMA (0.60 g, $6 \mathrm{mmol})$, MAA (0.17 g, $2 \mathrm{mmol}$ ), and $\operatorname{Ir}(\text { ppy })_{3}\left(0.026 \mathrm{mg}, 4.0 \times 10^{-5} \mathrm{mmol}\right)$ was first prepared in a glass vial sealed with a rubber septum. The mixture was deoxygenated by 3 cycles of freezing-pumping-thawing and irradiated under blue LED light strips (10 W, 460-470 nm) at room temperature. The polymerization lasted $12 \mathrm{~h}$ and the final mixture was purified via precipitation in cold diethyl ether 3 times. $M_{\mathrm{n}, \mathrm{NMR}}=35830 \mathrm{~g} \mathrm{~mol}{ }^{-1}, M_{\mathrm{w}} / M_{\mathrm{n}}=1.28 .{ }^{1} \mathrm{H} \mathrm{NMR}$ $\left(\mathrm{DMSO}-d_{6}\right): \delta$ (ppm): $0.84,0.97 \quad\left(3 \mathrm{H}, \quad \mathrm{CH}_{2} \mathrm{C}\left(\mathrm{CH}_{3}\right)\right), \quad 1.85$ $\left(2 \mathrm{H}, \mathrm{CH}_{2} \mathrm{C}\left(\mathrm{CH}_{3}\right)\right), 2.40\left(2 \mathrm{H}, \mathrm{CH}_{2} \mathrm{CHCl}\right), 3.51\left(3 \mathrm{H}, \mathrm{OCH}_{3}\right), 4.61$ $\left(1 \mathrm{H}, \mathrm{CH}_{2} \mathrm{CHCl}\right), 12.40(1 \mathrm{H}, \mathrm{COOH})$.

\section{"ON-OFF" control of photo-mediated polymerization of PFMA}

To demonstrate temporary controlled polymerization, a reaction solution consisting of DMF $(3 \mathrm{~mL})$, PVC $\left(M_{\mathrm{n}, \mathrm{GPC} / \mathrm{MALS}}=\right.$ $\left.12850 \mathrm{~g} \mathrm{~mol}^{-1}, M_{\mathrm{w}} / M_{\mathrm{n}}=1.14,0.21 \mathrm{~g}\right)$, PFMA (2.02 g, $\left.8 \mathrm{mmol}\right)$, and $\operatorname{Ir}(\text { ppy })_{3}\left(0.026 \mathrm{mg}, 4.0 \times 10^{-5} \mathrm{mmol}\right)$ was first prepared in a glass vial sealed with a rubber septum. The mixture was deoxygenated by 3 cycles of freezing-pumping-thawing and exposed to alternating light "ON" and "OFF" environments (blue LED light strips, $10 \mathrm{~W}, 460-470 \mathrm{~nm}$ ). At a certain time interval, an aliquot of reaction mixture was taken for analysis of monomer conversion, molecular weight, and molecular weight distribution using ${ }^{1} \mathrm{H}$ NMR and GPC.

\section{Kinetics of photo-mediated polymerization of PFMA in the presence of oxygen}

A reaction solution consisting of DMF (3 $\mathrm{mL})$, PVC $\left(M_{\mathrm{n}, \mathrm{GPC} / \mathrm{MALS}}=12850 \mathrm{~g} \mathrm{~mol}^{-1}, M_{\mathrm{w}} / M_{\mathrm{n}}=1.14,0.21 \mathrm{~g}\right)$, PFMA $(2.02 \mathrm{~g}, 8 \mathrm{mmol})$, and $\operatorname{Ir}(\text { ppy })_{3}\left(0.26 \mathrm{mg}, 4.0 \times 10^{-4} \mathrm{mmol}\right)$ was first prepared in a glass vial sealed with a rubber septum. The mixture was irradiated under blue LED light strips $(10 \mathrm{~W}$, 460-470 $\mathrm{nm}$ ) at room temperature without deoxygenation. At a certain time interval, an aliquot of reaction mixture was taken for analysis of monomer conversion, molecular weight, and molecular weight distribution using ${ }^{1} \mathrm{H}$ NMR and GPC. 


\section{Surface modification of PVC sheets by surface grafting}

In a typical procedure, a PVC sheet $(5 \mathrm{~cm} \times 3 \mathrm{~cm})$ was put into a solution consisting of DMSO (20 mL), PFMA (2.02 g, $8 \mathrm{mmol})$, and $\operatorname{Ir}(\mathrm{ppy})_{3}\left(0.26 \mathrm{mg}, 4.0 \times 10^{-4} \mathrm{mmol}\right)$ in a glass vial. The vial was sealed with a rubber septum and the reaction solution was irradiated under blue LED light strips $(10 \mathrm{~W}$, 460-470 nm) at room temperature without deoxygenation. The reaction lasted $6 \mathrm{~h}$ and the PVC sheet was taken out and washed with DMSO repeatedly until no phenyl signal was detected by ${ }^{1} \mathrm{H}$ NMR in DMSO eluent.

\section{Photo-patterning of 'SIOC' image on PVC sheets}

A PVC sheet $(5 \mathrm{~cm} \times 3 \mathrm{~cm})$ was put into a solution consisting of DMSO $(20 \mathrm{~mL})$, PFMA $(2.02 \mathrm{~g}, 8 \mathrm{mmol})$, and $\operatorname{Ir}(\mathrm{ppy})_{3}$ $\left(0.26 \mathrm{mg}, 4.0 \times 10^{-4} \mathrm{mmol}\right)$ in a glass vial. The vial was covered with a photo-mask with an 'SIOC' pattern hole, so the light can only pass through the 'SIOC' hole. The vial was sealed with a rubber septum and the solution was irradiated under blue LED light strips ( $10 \mathrm{~W}, 460-470 \mathrm{~nm}$ ) at room temperature without deoxygenation. The reaction lasted $24 \mathrm{~h}$ and the PVC sheet was taken out and washed with DMSO repeatedly until no phenyl signal was detected by ${ }^{1} \mathrm{H}$ NMR in DMSO eluent, affording a spatially modified PVC sheet.

For a control experiment, another PVC sheet was immersed into a solution of PFMA $(2.02 \mathrm{~g}, 8 \mathrm{mmol})$ in DMSO $(20 \mathrm{~mL})$ without $\operatorname{Ir}(\mathrm{ppy})_{3}$, and irradiated with a fluorescent lamp for $24 \mathrm{~h}$ through the same photo-mask under the same conditions.

\section{Contact angle measurements}

Static contact angle measurements of deionized water on surface modified PVC sheets were performed using a JC2000C instrument at ambient conditions. Water contact angles were measured after allowing water droplets to equilibrate on the surface for $30 \mathrm{~s}$. Measurements were repeated on at least three different spots on every sheet. The final reported values represent an average of the measurements.

\section{Results and discussion}

\section{Graft copolymerization of methacrylate monomers in the absence of oxygen}

Encouraged by contributions from the groups of MacMillan, Stephenson, Yoon, and others on $\mathrm{Ru}^{-}$and Ir-based photoredox catalysts for organic transformations, ${ }^{35-38}$ Hawker et al. developed photo-chemically mediated controlled/living ATRP by employing Ir-based photo-redox catalysts. They proposed that the excited photocatalyst with absorption of visible light with a certain wavelength could reduce $\mathrm{C}-\mathrm{Br}$ bonds to afford desired alkyl radicals for initiating polymerization. We hypothesize that this chemistry can be employed to directly functionalize PVC by using the structural defects of the allyl chloride and tertiary chloride groups of commercial PVC as initiating sites, similar to $\mathrm{C}-\mathrm{Br}$ bonds. To evaluate this hypothesis, polymerization of MMA was firstly investigated using commercially available PVC $\left(M_{\mathrm{n}, \mathrm{GPC} / \mathrm{MALS}}=12850 \mathrm{~g} \mathrm{~mol}^{-1}, M_{\mathrm{w}} / M_{\mathrm{n}}=\right.$ 1.14) as a macroinitiator, $\mathrm{Ru}(\mathrm{bpy})_{3} \mathrm{Cl}_{2}$ or $\operatorname{Ir}(\mathrm{ppy})_{3}$ as a photocatalyst, and a blue LED light source (10 W, 460-470 nm) in DMF (Table 1). We found that the conversion of MMA reached $66 \%$ with a broad molecular weight distribution of 1.68 after $24 \mathrm{~h}$ for the reaction using $\operatorname{Ir}(\mathrm{ppy})_{3}$ with a concentration of $0.2 \mathrm{~mol} \%$ as the photo-redox catalyst (entry 5 in Table 1). As the amount of catalyst was cut to $0.0005 \mathrm{~mol} \%$, the conversion was $49 \%$, affording a product with a narrow molecular weight distribution of 1.31 (entry 1 in Table 1). As the amount of catalyst was cut further to $0.00001 \mathrm{~mol} \%$, the polymerization became slow with a conversion of $28 \%$, also providing a product with a narrow molecular weight distribution of 1.32 (entry 6 in Table 1). This phenomenon is consistent with previous work, ${ }^{29}$ which suggested that part of the photo-redox catalyst might act as an initiator (to produce PMMA homopolymer) for the polymerization with a high amount of catalyst.

Fig. 1 shows the ${ }^{1} \mathrm{H}$ NMR spectra and GPC curves of pristine PVC and functionalized PVC after graft copolymerization of MMA. One can clearly notice the characteristic multiplet

Table 1 Synthesis of PVC-based graft copolymers under different conditions ${ }^{a}$

\begin{tabular}{|c|c|c|c|c|c|c|c|}
\hline Entry & Monomer & Ir (mol\%) & Time (h) & $f^{e}(\mathrm{~mol} \%)$ & $M_{\mathrm{n}}^{f}$ & $M_{\mathrm{w}} / M_{\mathrm{n}}{ }^{g}$ & Conv. ${ }^{h}$ \\
\hline 1 & MMA & 0.0005 & 24 & 30.7 & 24750 & 1.31 & $49 \%$ \\
\hline $2^{b}$ & MMA & 0.0005 & 24 & - & - & - & n.d. \\
\hline $3^{c}$ & MMA & 0.0005 & 24 & - & - & - & n.d. \\
\hline $4^{d}$ & MMA & 0 & 24 & - & - & - & n.d. \\
\hline 5 & MMA & 0.2 & 24 & 46.1 & 29000 & 1.68 & $66 \%$ \\
\hline 6 & MMA & 0.00001 & 24 & 19.2 & 19610 & 1.32 & $28 \%$ \\
\hline 7 & PFMA & 0.0005 & 20 & 38.1 & 44240 & 1.29 & $24 \%$ \\
\hline 8 & OEGMA & 0.001 & 12 & 37.6 & 77470 & 1.28 & $22 \%$ \\
\hline $9^{i}$ & MMA & 0.005 & 24 & 16.7 & 18200 & 1.22 & $22 \%$ \\
\hline $10^{i}$ & PFMA & 0.005 & 12 & 46.5 & 51770 & 1.39 & $30 \%$ \\
\hline
\end{tabular}

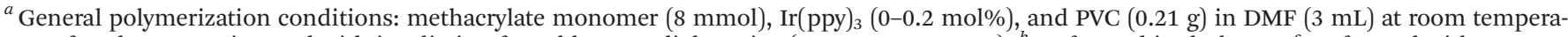

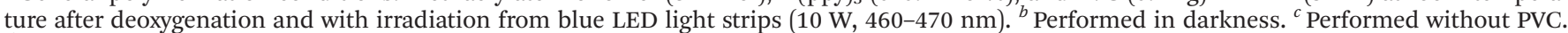

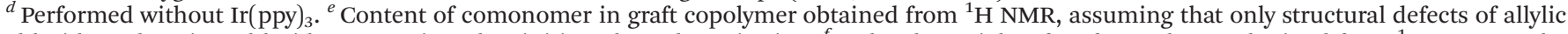

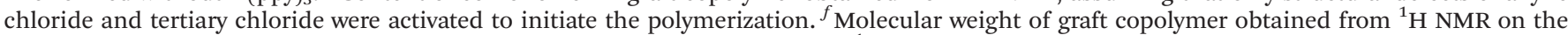

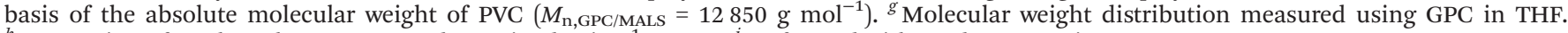

${ }^{h}$ Conversion of methacrylate monomer determined using ${ }^{1} \mathrm{H}$ NMR. ${ }^{i}$ Performed without deoxygenation. 


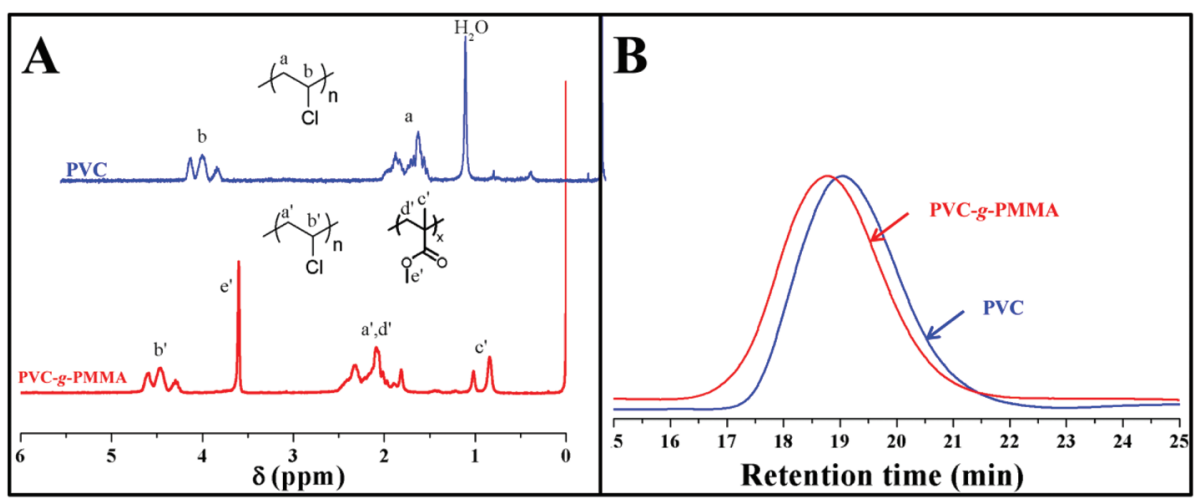

Fig. $1{ }^{1} \mathrm{H}$ NMR spectra (A) and GPC curves (B) of pristine PVC and PVC-g-PMMA.

around $4.46 \mathrm{ppm}(\mathrm{b})$, attributed to 1 methine proton of PVC, and typical peaks at $0.84\left(\mathrm{c}^{\prime}\right)$ and $3.60\left(\mathrm{e}^{\prime}\right) \mathrm{ppm}$, originating from 3 methyl protons and 3 methoxy protons of the PMMA segment in the ${ }^{1} \mathrm{H}$ NMR spectrum of the PVC-g-PMMA graft copolymer. Furthermore, the functionalized PVC after graft copolymerization of MMA showed a unimodal and symmetrical eluent peak with a higher molecular weight than that of the pristine PVC and a narrow molecular weight distribution $\left(M_{\mathrm{w}} / M_{\mathrm{n}}=1.22\right)$. These observations verified the successful grafting of PMMA chains from PVC segments and preservation of most of the $\mathrm{C}-\mathrm{Cl}$ bonds of PVC.

In order to confirm that the polymerization was only induced by the $\operatorname{Ir}(\mathrm{ppy})_{3}$ photo-redox catalyst under light in the presence of PVC, control experiments without the addition of the catalyst or PVC, or in the absence of light were performed. Polymerization was not detected in these cases (entries 2, 3, and 4 in Table 1) as indicated by no conversion of MMA monomer. These results evidenced that the polymerization was indeed a photo-mediated process initiated by PVC and catalyzed by $\operatorname{Ir}(\mathrm{ppy})_{3}$ under light irradiation. Particularly, almost no monomer was consumed for the control experiment without PVC (entry 3 in Table 1). Thus, we might exclude the possibility that polymers were formed firstly by self-initiation and subsequently grafted on the PVC by chain transfer. It should be noted that the polymerization did not occur while using $\mathrm{Ru}(\mathrm{bpy})_{3} \mathrm{Cl}_{2}$ as a photo-catalyst. Previous reports ${ }^{39,40}$ suggested that the activity of the photocatalyst is dependent on its redox potential. The redox potential of $\operatorname{Ir}^{(\mathrm{IV})} / \mathrm{Ir}^{(\mathrm{III})} *$ is $1.73 \mathrm{~V}$ vs. a saturated calomel electrode, much higher than that of $\mathrm{Ru}^{(\mathrm{III})} / \mathrm{Ru}^{(\mathrm{III}) *}(0.81 \mathrm{~V}) .^{40}$ Thus, $\mathrm{Ru}(\mathrm{bpy}){ }_{3} \mathrm{Cl}_{2}$ with a low redox potential might be not active enough for the homolysis of $\mathrm{C}-\mathrm{Cl}$ bonds of $\mathrm{PVC}$ to initiate the polymerization.

Subsequently, we tested the versatility of this strategy for functionalization of PVC by graft polymerization of other methacrylate monomers, where PFMA, a widely used and efficient building block for postfunctionalization, ${ }^{41-43}$ and OEGMA, a popular monomer for the preparation of antifouling materials, ${ }^{44,45}$ were used as examples (entries 7 and 8 in Table 1) for the polymerization under similar conditions. We also observed the formation of PVC-g-PPFMA and PVC$g$-POEGMA graft copolymers with narrow molecular weight distributions $\left(M_{\mathrm{w}} / M_{\mathrm{n}} \leq 1.29\right)$ (Fig. S2 and S3 $\uparrow$ ). Moreover, one of attractive advantages of photo-mediated ATRP using $\operatorname{Ir}(\mathrm{ppy})_{3}$ as the photo-redox catalyst over conventional ATRP is its capacity to polymerize acidic monomers, for example MAA, which would poison basic multidentate-amine-based catalysts for conventional ATRP. We then attempted to conduct random copolymerization of MAA and MMA with different feeding ratios of MAA to MMA by employing similar conditions for the polymerization of MMA: $0.0005 \mathrm{~mol} \%$ of $\operatorname{Ir}(\mathrm{ppy})_{3}$ with irradiation by $460 \mathrm{~nm}$ blue LEDs. Fig. $2 \mathrm{~A}$ shows the ${ }^{1} \mathrm{H}$ NMR spectrum of PVC- $g$-(PMMA-co-PMAA). Besides the typical peaks at $4.41 \mathrm{ppm}(\mathrm{b})$ of the $\mathrm{VC}$ repeated unit and $3.51 \mathrm{ppm}(\mathrm{e})$ of the MMA repeated unit, one can also notice the characteristic

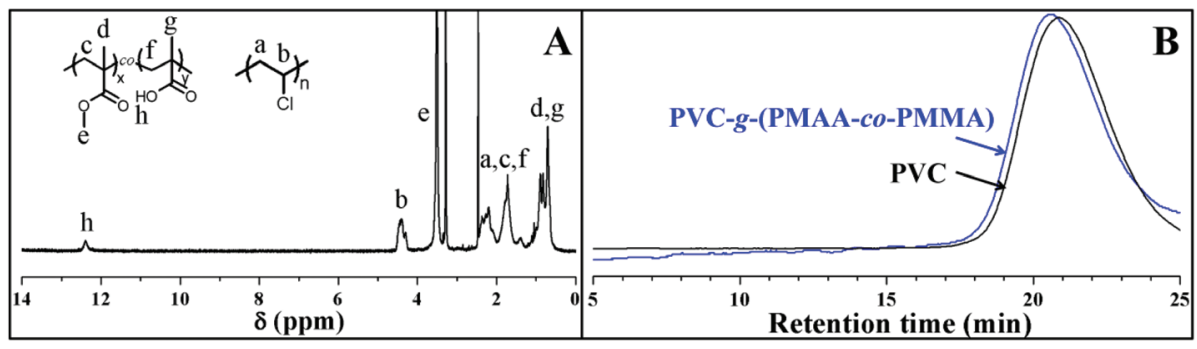

Fig. 2 (A) ${ }^{1} \mathrm{H}$ NMR spectrum of PVC-g-(PMMA-Co-PMAA) with a feeding ratio of MAA to MMA of $25: 75$ in DMSO- $d_{6}$ and (B) GPC traces of pristine PVC and PVC-g-(PMMA-Co-PMAA) with a feeding ratio of MAA to MMA of $25: 75$ in DMF. 
Table 2 Synthesis of PVC-g-(PMMA-co-PMAA) under different conditions ${ }^{a}$

\begin{tabular}{|c|c|c|c|c|c|c|c|}
\hline Entry & {$[\mathrm{MAA}]:[\mathrm{MMA}]$} & $f_{\mathrm{MAA}}{ }^{b}(\mathrm{~mol} \%)$ & $f_{\mathrm{MMA}}{ }^{b}(\mathrm{~mol} \%)$ & $M_{\mathrm{n}}{ }^{c}$ & $M_{\mathrm{w}} / M_{\mathrm{n}}{ }^{d}$ & Conv. $^{e}$ (MAA) & Conv. $^{e}$ (MMA) \\
\hline 1 & $25: 75$ & $11 \%$ & $49 \%$ & 35830 & 1.28 & $40 \%$ & $50 \%$ \\
\hline 2 & $50: 50$ & $30 \%$ & $39 \%$ & 29070 & 1.30 & $31 \%$ & $39 \%$ \\
\hline
\end{tabular}

${ }^{a}$ General polymerization conditions: MMA (0-0.60 g), MAA (0.17 g-0.69 g), Ir(ppy) $(0.0005 \mathrm{~mol} \%)$, and PVC (0.21 g) in DMF (3 mL) at room temperature after deoxygenation and with irradiation from blue LED light strips $(10 \mathrm{~W}, 460-470 \mathrm{~nm}) .{ }^{b}$ Content of comonomer in graft copolymer obtained from ${ }^{1} \mathrm{H}$ NMR, assuming that only structural defects of allylic chloride and tertiary chloride were activated to initiate the polymerization. ${ }^{c}$ Molecular weight of graft copolymer obtained from ${ }^{1} \mathrm{H}$ NMR on the basis of the absolute molecular weight of PVC $\left(M_{\mathrm{n}, \mathrm{GPC} / \mathrm{MALS}}=12850 \mathrm{~g}\right.$ $\mathrm{mol}^{-1}$ ). ${ }^{d}$ Molecular weight distribution measured using GPC in DMF. ${ }^{e}$ Conversion of monomer determined using ${ }^{1} \mathrm{H}$ NMR.

peak at $12.40 \mathrm{ppm}(\mathrm{h})$ originating from 1 carboxyl proton in the MAA repeated unit. Furthermore, PVC- $g$-(PMMA-co-PMAA) also showed a unimodal and symmetrical eluent peak with a higher molecular weight than that of pristine PVC and a narrow molecular weight distribution $\left(M_{\mathrm{w}} / M_{\mathrm{n}}=1.28\right)$. It should be pointed out that the obtained products, especially the products formed with the feeding ratios of MAA to MMA of $50: 50$ and $100: 0$, showed good solubility in methanol, which is a bad solvent for PVC and PMMA. These observations clearly demonstrated the successful introduction of PMAA segments into the PVC backbone. The results of the copolymerization of MMA and MAA are summarized in Table 2. All PMAA-containing copolymers showed narrow molecular weight distributions $\left(M_{\mathrm{w}} / M_{\mathrm{n}} \leq 1.30\right)$, even for the polymerization without MMA, the molecular weight distribution of the copolymer is just 1.30. These results might indicate good control over the (co) polymerization of MAA under the current conditions.

One might argue that the product might be a blend of homopolymer of PVC and PMAA or PMMA- $g$-PMAA due to a slight increase in the molecular weight of the product compared to pristine PVC as shown in Fig. 2B. In order to clarify this point, we conducted a control experiment, in which we added $5 \mathrm{~mL}$ of water into a bottle containing $15 \mathrm{mg}$ of PVC$g$-PMAA and $5 \mathrm{~mL}$ of water into another bottle containing $5 \mathrm{mg}$ of PVC homopolymer and $10 \mathrm{mg}$ of PAA homopolymer. After shaking, the PVC- $g$-PMAA copolymer was dissolved in water directly (Fig. S4†). The solution was transparent and one can notice the Tyndall effect. On the contrary, one can clearly see white powders of PVC on the wall of the bottle (Fig. S4†). The water solubility of PVC-g-PMAA and the Tyndall effect of the obtained solution indicated that micelles with a hydrophobic PVC core and hydrophilic PMAA corona were formed in water for PVC- $g$-PMAA. Therefore, the obtained PVC- $g$-PMAA was not a blend of PVC and PMAA. In addition, an extraction experiment on the obtained PVC-g-POEGMA also showed that the obtained product of PVC- $g$-POEGMA copolymer was not a blend of homopolymer of PVC and POEGMA (Fig. S5†). In summary, this method showed robust nature in direct functionalization of PVC by photo-mediated ATRP of methacrylate monomers.

To demonstrate the advantage of the temporally controlled ability of photo-mediated ATRP for PVC functionalization, a mixture of PFMA, PVC, and $\operatorname{Ir}(\text { ppy })_{3}$ was exposed to alternating light "ON" and "OFF" environments after the deoxygenation procedure. Gratifyingly, as shown in Fig. 3, the system almost remained dormant with nearly no polymerization proceeding in the absence of light, when the light was back "ON", the system was activated and the polymerization recovered. These "activation" and "deactivation" processes clearly illustrated that the polymerization can be easily manipulated by controlling "ON" and "OFF" periods of light. In addition, the plot of $\ln \left([\mathrm{M}]_{0} /[\mathrm{M}]_{t}\right)$ vs. exposure time gave a linear relationship, indicative of a constant propagating radical concentration. The molecular weight of the PVC- $g$-PPFMA graft copolymer, obtained from ${ }^{1} \mathrm{H}$ NMR, also gradually increased with exposure time and the molecular weight distributions kept narrow $\left(M_{\mathrm{w}}\right)$ $M_{\mathrm{n}} \leq 1.29$ ). A linear relationship was also observed in the plot of $M_{\mathrm{n}}$ of the PVC- $g$-PMMA graft copolymer against conversion of MMA and $\ln \left([\mathrm{M}]_{0} /[\mathrm{M}]_{t}\right)$ vs. exposure time (Fig. S6†).

\section{Examination on possible initiating sites for graft copolymerization}

Starnes et al. have systematically examined the mechanism of formation and contents of defects (allylic and tertiary chlorides), and thermal stability and degradation mechanism of PVC obtained by radical polymerization under different conditions. ${ }^{46}$ They estimated the content of allylic chlorides in PVC using ${ }^{1} \mathrm{H}$ NMR and their results showed that there was about 0.8-1.1 double bonds (allylic chloride) per PVC chain and there was still about 0.1-0.6 double bonds per $1000 \mathrm{VC}$ repeated units in the middle of the polymer chains depending on the preparation conditions, though most of the double bonds were at the end of the polymer chains. In the current work, a similar method was used to estimate the content of allylic chloride using ${ }^{1} \mathrm{H}$ NMR (Fig. S7 $\dagger$ ). There were about 0.8 terminal and 0.1 internal allylic chlorides in each PVC chain. These values are close to the results reported in previous literatures. ${ }^{46-48}$ They also have done a lot of work to measure the content of tertiary chloride of different PVC samples prepared by radical polymerization under different conditions. Based on their results, there were about 0.5-2.0 tertiary chlorides per $1000 \mathrm{VC}$ repeated units. ${ }^{49}$ Thus, there were about 205 VC repeated units in each chain, and there was about 0.1-0.4 tertiary chlorides per PVC chain.

In the current case, a $\operatorname{Ir}(\mathrm{ppy})_{3}$ photo-redox catalyst was employed for graft polymerization for commercial PVC. 


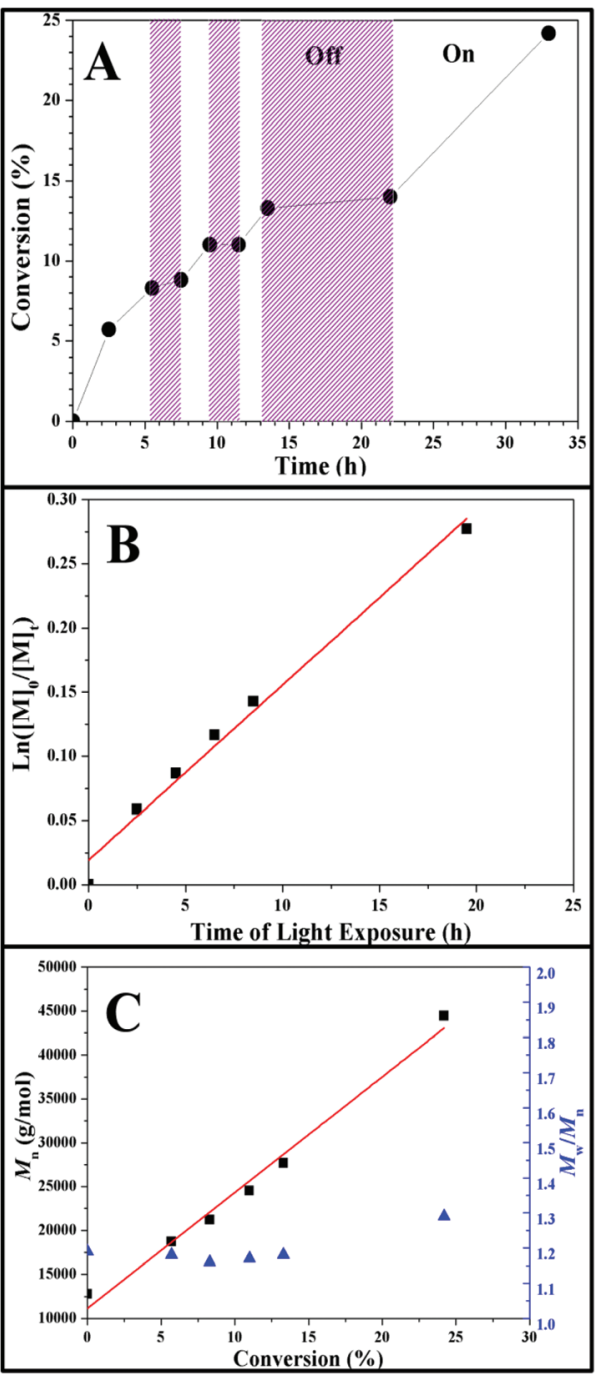

Fig. 3 Photo-mediated ATRP of PFMA using PVC as the initiator and $\operatorname{Ir}(\mathrm{ppy})_{3}$ as the photocatalyst in the presence ("ON") or in the absence ("OFF") of light: (A) conversion vs. time, (B) $\ln \left([\mathrm{M}]_{0} /[\mathrm{M}]_{t}\right)$ vs. exposure time, and (C) $M_{n}$ and $M_{w} / M_{n}$ vs. conversion of PFMA. Polymerization conditions: $[\mathrm{PFMA}]:\left[\operatorname{lr}(\mathrm{ppy})_{3}\right]=100: 0.0005,[\mathrm{PVC}]=0.07 \mathrm{~g} \mathrm{~mL}^{-1}$, $[P F M A]=2.67 \mathrm{~mol} \mathrm{~L}^{-1}$, room temperature, blue LED light strips $(10 \mathrm{~W}$, $460-470 \mathrm{~nm})$, deoxygenation by three cycles of freezing-pumpingthawing.

Although the secondary $\mathrm{C}-\mathrm{Cl}$ bonds of normal VC repeated units with a bond dissociation energy of $81.8 \mathrm{kcal} \mathrm{mol}^{-1}$ are much stronger than that of allylic chloride $\left(65.4 \mathrm{kcal} \mathrm{mol}^{-1}\right)$, but just $1.7 \mathrm{kcal} \mathrm{mol}^{-1}$ higher than that of tertiary chloride $\left(80.1 \mathrm{kcal} \mathrm{mol}^{-1}\right),{ }^{50,51}$ one might argue that the secondary $\mathrm{C}-\mathrm{Cl}$ groups might also be activated by the $\operatorname{Ir}(\mathrm{ppy})_{3}$ photocatalyst and act as initiating sites in the polymerization. In order to examine the initiation behaviors of PVC with defects, we performed polymerizations using model compounds of allylic chloride (3-chloride-propene), tertiary chloride (tertbutyl chloride), and secondary chloride (isopropyl chloride), respectively, instead of PVC (Table S1 $\dagger$ ). We found that all of 3-chloride-propene, tert-butyl chloride, and isopropyl chloride could serve as initiators for polymerization of MMA. It should be pointed out that isopropyl chloride also can initiate the polymerization, though the conversion of MMA using isopropyl chloride $(5.1 \%)$ was lower than those using 3-chloridepropene (9.1\%) and tert-butyl chloride (9.9\%). We speculated that the lower reactivity of the secondary chloride might result in a lower monomer conversion compared to the polymerizations using the allylic chloride and tertiary chloride as initiators. As mentioned above, there were about 0.9 allylic chlorides and 0.1-0.5 tertiary chlorides in each PVC chain, while there were about 204 secondary chlorides in each PVC chain. Although the initiation efficiency of the secondary chloride $(2.1 \%)$ was lower than those of allylic $(3.4 \%)$ and tertiary $(3.2 \%)$ chlorides, and $\mathrm{C}-\mathrm{Cl}$ bonds of allylic and tertiary chlorides with a bond dissociation energy of 65.4 and $80.1 \mathrm{kcal} \mathrm{mol}^{-1}$, respectively, are weaker than that of the secondary chloride $\left(81.8 \mathrm{kcal} \mathrm{mol}^{-1}\right)$, the content of secondary chlorides is much higher than that of allylic and tertiary chlorides in the PVC chain. ${ }^{50,51}$ Especially, our on-going work on surface functionalization of fluorinated graphene showed that $\mathrm{C}-\mathrm{F}$ bonds of fluorinated graphene can even be activated by a $\operatorname{Ir}(\mathrm{ppy})_{3}$ photo-redox catalyst. Thus, some of the secondary chlorides were probably activated and served as initiating sites for the polymerization in the current case.

In order to quantify the amount of activated secondary chlorides, we monitored the integration area of peak ' $a$ ' at $4.46 \mathrm{ppm}$ (Fig. 4), which was attributed to 1 methine proton of PVC over the polymerization of MMA using anisole as an internal standard (peak 'd'). The results demonstrated that less than $2.1 \%$ of secondary chlorides of $\mathrm{VC}$ repeated units were activated and served as initiating sites for polymerization, while a large majority of secondary chlorides kept inert during

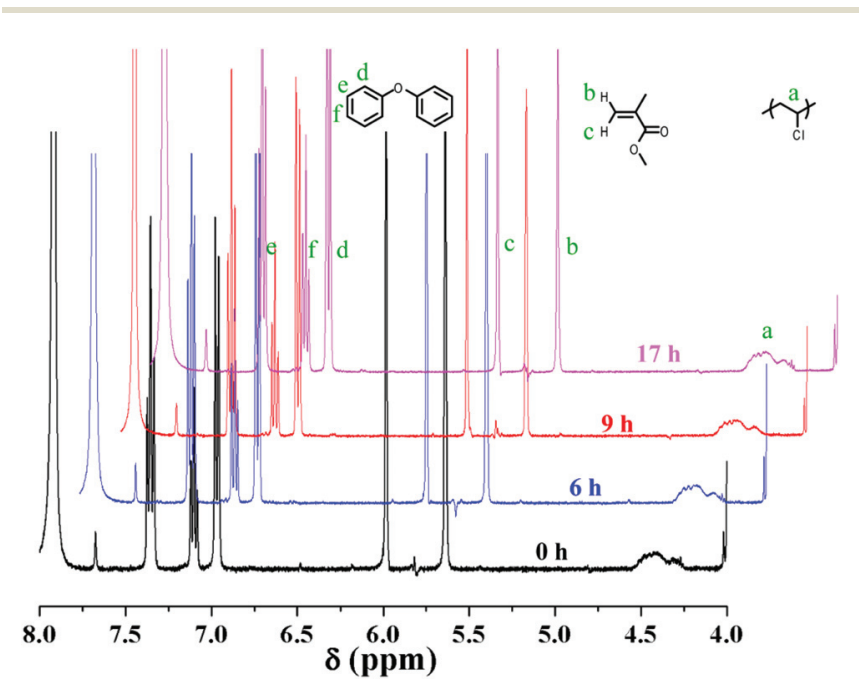

Fig. $4{ }^{1} \mathrm{H}$ NMR spectra of a polymerization solution at different times using diphenyl ether as an internal standard. Polymerization conditions: MMA $(0.80 \mathrm{~g}, 8 \mathrm{mmol}), \operatorname{Ir}(\mathrm{ppy})_{3}(0.0005 \mathrm{~mol} \%)$, PVC $(0.21 \mathrm{~g})$, DMF $(3.0 \mathrm{~mL})$ and diphenyl ether $(200 \mu \mathrm{L})$, room temperature with irradiation from blue LED light strips ( $10 \mathrm{~W}, 460-470 \mathrm{~nm}$ ), deoxygenation by three cycles of freezing-pumping-thawing. 
the polymerization. We speculated that after allylic and tertiary chlorides, along with some of the secondary chlorides, were activated and initiated the polymerization of methacrylatebased monomer, these chlorides were transferred to the end of methacrylate-based polymeric chains. These $\mathrm{C}-\mathrm{Cl}$ bonds at the chain ends of the methacylate-based polymeric chains with a dissociation energy of $66.9 \mathrm{kcal} \mathrm{mol}^{-1}$ were much weaker than that of the secondary chlorides, ${ }^{50,51}$ which can be homolyzed much easier for initiating the polymerization. Therefore, just a small amount of the secondary chlorides of the VC repeated units seemed to be activated for initiating the polymerization while a large majority of the VC repeated units were maintained.

\section{Graft copolymerization of methacrylate monomers without deoxygenation}

Since oxygen is a typical radical scavenger, it will be detrimental to radical polymerization, especially for controlled/living radical polymerizations such as RAFT, ${ }^{52} \mathrm{NMP}^{53}$ and ATRP. ${ }^{54}$ Therefore, a deoxygenation process of freeze-pump-thaw cycles or degassing with $\mathrm{N}_{2}$ is usually required for these polymerizations. For industrial application of these techniques, deoxygenation processes will inevitably require some specific facilities and extra cost to construct an oxygen-free environment. To solve this puzzle, Matyjaszewski and Percec et al. developed AGET \& SARA ATRP, and SET-LRP processes, ${ }^{55-59}$ which can be performed without deoxygenation. Recently, Boyer et al. reported that $\operatorname{Ir}(\mathrm{ppy})_{3}$ could reduce oxygen into inactive species upon light irradiation and they demonstrated the polymerization of a large range of monomers in a well-controlled fashion by using $\operatorname{Ir}(\mathrm{ppy})_{3}$ as a photo-redox catalyst. ${ }^{60,61}$ Although Hawker et al. developed photo-mediated ATRP of acrylate- and methacrylate-based monomers by using $\operatorname{Ir}(\mathrm{ppy})_{3}$ as photo-redox catalyst ${ }^{29,30}$ and fabricated attractive surface patterns by this technique, ${ }^{31}$ these polymerizations were conducted in an oxygen-free environment. Inspired by Boyer's contributions, ${ }^{60,61}$ we hypothesize that the functionalization of PVC via photo-mediated ATRP catalyzed by $\operatorname{Ir}(\mathrm{ppy})_{3}$ might be performed without prerequisite of deoxygenation since oxygen can be slowly reduced into inactive species by $\operatorname{Ir}(\mathrm{ppy})_{3}$ upon light irradiation.

To test this hypothesis, we first ran a polymerization of MMA in a $10 \mathrm{~mL}$ sealed but non-degassed flask containing $0.80 \mathrm{~g}$ of MMA, $3 \mathrm{~mL}$ of DMF, $0.21 \mathrm{~g}$ of PVC, and $0.0005 \mathrm{~mol} \%$ of $\operatorname{Ir}(\mathrm{ppy})_{3}$ under the irradiation of blue light at room temperature. After $24 \mathrm{~h}$, it seemed that the polymerization did not proceed and just a trace of MMA was consumed. We speculated that the amount of $\operatorname{Ir}(\mathrm{ppy})_{3}$ might be not adequate enough to reduce $\mathrm{O}_{2}$ in the flask over $24 \mathrm{~h}$. Then, we ran the same reaction with $0.005 \mathrm{~mol} \%$ of $\operatorname{Ir}(\mathrm{ppy})_{3}$. Satisfyingly, a $22 \%$ monomer conversion was detected by ${ }^{1} \mathrm{H}$ NMR after $24 \mathrm{~h}$ (entry 9 in Table 1) for affording a PVC-g-PMMA graft copolymer with a higher molecular weight compared to pristine PVC and a narrow molecular weight distribution $\left(M_{\mathrm{w}} / M_{\mathrm{n}}=1.22\right)$. Under similar conditions, PVC-g-PPFMA (entry 10 in Table 1 ) was also obtained with a relatively narrow molecular weight distribution $\left(M_{\mathrm{w}} / M_{\mathrm{n}}=1.39\right)$.

Subsequently, we examined the polymerization kinetics of PFMA without the deoxygenation procedure under the same conditions. It was found from Fig. 5 that after light irradiation for $4 \mathrm{~h}$, almost no monomer was consumed and the monomer conversion was 0 ; as the irradiation continued for another $1 \mathrm{~h}$, the polymerization proceeded and $6.1 \%$ of PFMA was consumed. The monomer conversion further increased to $26.1 \%$ after $8 \mathrm{~h}$. After the light was turned off, the polymerization seemed to remain dormant and the monomer conversion only increased to $26.2 \%$ after another $8 \mathrm{~h}$ in darkness. However, as the light was turned on, the polymerization seemed to wake up and the conversion further increased to $38.7 \%$ after irradiation

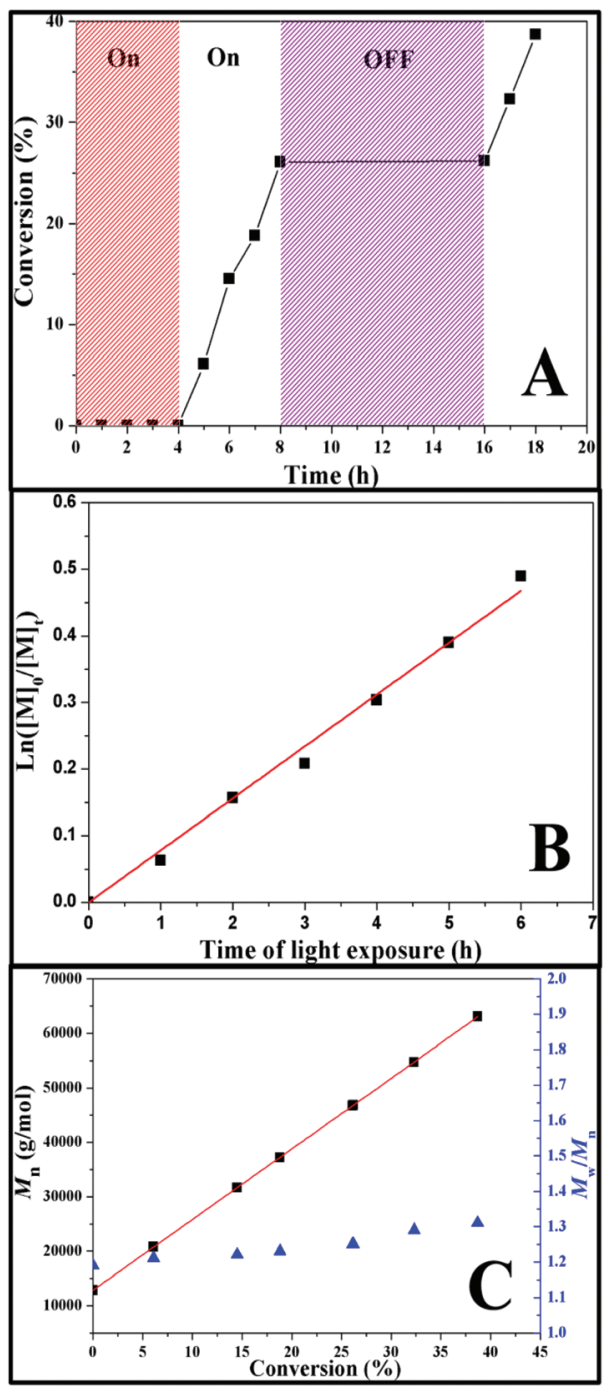

Fig. 5 Photo-mediated ATRP of PFMA using PVC as the initiator and $\operatorname{Ir}(\mathrm{ppy})_{3}$ as the photocatalyst in the presence ("ON") or in the absence ("OFF") of light without the deoxygenation procedure: (A) conversion vs. time, (B) $\ln \left([\mathrm{M}]_{0} /[\mathrm{M}]_{t}\right)$ vs. exposure time, and (C) $M_{\mathrm{n}}$ and $M_{\mathrm{w}} / M_{\mathrm{n}}$ vs. conversion of PFMA. Polymerization conditions: $[\mathrm{PFMA}]:\left[\operatorname{lr}(\mathrm{ppy})_{3}\right]=$ $100: 0.005,[P V C]=0.07 \mathrm{~g} \mathrm{~mL}^{-1},[P F M A]=2.67 \mathrm{~mol} \mathrm{~L}^{-1}$, room temperature, blue LED light strips ( $10 \mathrm{~W}, 460-470 \mathrm{~nm}$ ). 
for $2 \mathrm{~h}$ again. In addition, the plot of $\ln \left([\mathrm{M}]_{0} /[\mathrm{M}]_{t}\right)$ vs. light exposure time gave a linear relationship after the inhibition time and the molecular weight of the copolymer also increased linearly with monomer conversion, accompanied with narrow molecular weight distributions $\left(M_{\mathrm{w}} / M_{\mathrm{n}} \leq 1.31\right)$. These observations showed that the presence of air would lead to a long inhibition time, which might be attributed to the reduction of oxygen by $\operatorname{Ir}(\mathrm{ppy})_{3}$. Although the polymerization system was not deoxygenated, the polymerization still proceeded in a controlled/living manner and the temporally controlled capacity of polymerization was not affected.

\section{Functionalization of the surface of PVC sheets without a deoxygenation procedure}

On the basis of these preliminary but satisfying results, we decided to test the application of this method for surface modification of PVC-based materials. It should be pointed out that the polymerization can be performed without a deoxygenation procedure, which will make this technique much more attractive for surface modification since construction of an oxygen-free environment could be a challenge and require extra costs in industry for surface modification by surfaceinitiated ATRP.

We used a commercially available PVC sheet as a model PVC-based material, and PFMA was selected as a model monomer. The reasons for choosing PFMA were twofold: firstly, PPFMA is a typical fluoropolymer with a low surface energy for surface coating; secondly, pentafluorophenyl ester has a high reactivity toward amino and hydroxyl groups, ${ }^{4-43}$ which will result in a great variety of conjugates for introducing functional moieties and further tuning the surface properties of PVC. A PVC sheet with a length of about $50 \mathrm{~mm}$, a width of about $30 \mathrm{~mm}$, and a thickness of about $3 \mathrm{~mm}$ was partly immersed into DMSO solution containing PFMA $\left(0.4 \mathrm{~mol} \mathrm{~L}^{-1}\right)$ and $\operatorname{Ir}(\text { ppy })_{3}\left(2.0 \times 10^{-5} \mathrm{~mol} \mathrm{~L}^{-1}\right)$, and was exposed to the light (blue LED light strips, $10 \mathrm{~W}, 460-470 \mathrm{~nm}$ ) for $6 \mathrm{~h}$ without a deoxygenation procedure. After the sheet was rinsed with DMSO and dried in vacuo, the wettability of the PVC sheet with and without surface modification was studied by measuring the static water contact angle (Fig. 6). The surface water contact angles of pristine PVC and PFMA-treated PVC sheets are $74^{\circ}$ and $92^{\circ}$, respectively. The obvious increase in the water contact angle after the treatment with PFMA indicated the introduction of PPFMA segments onto the PVC surface. Subsequently, we attempted longer polymerization times (12 and $24 \mathrm{~h}$ ) for the polymerization of PFMA from PVC sheets under the same conditions. As shown in Fig. 6, the PVC sheets had surface water contact angles of $94^{\circ}$ and $99^{\circ}$ for the polymerization times of 12 and $24 \mathrm{~h}$, respectively, higher than that of PVC with a polymerization time of $6 \mathrm{~h}\left(92^{\circ}\right)$. This observation affirmed that the prolonging of polymerization time could lead to a more compact PPFMA layer. Moreover, in order to extend the application of this method, POEGMA, a widely used hydrophilic polymer for non-fouling surface modification, was grafted from PVC sheets with a feeding ratio of $[\mathrm{OEGMA}]:\left[\operatorname{Ir}(\mathrm{ppy})_{3}\right]=100: 0.005$ in DMSO at room temperature under irradiation of blue LED light strips $(10 \mathrm{~W}$, 460-470 nm). It can be noticed that the surface water contact angle of the PVC sheet dramatically decreased from $74^{\circ}$ to $11^{\circ}$ after the polymerization of OEGMA (Fig. 6B), which confirmed that the PVC surface was coated with hydrophilic POEGMA domains after the polymerization.

One might argue that the change of water contact angle after the polymerization might result from physical absorption, not formation of a PPFMA layer covalently attached onto the surface of the PVC sheet by surface-initiated ATRP. In

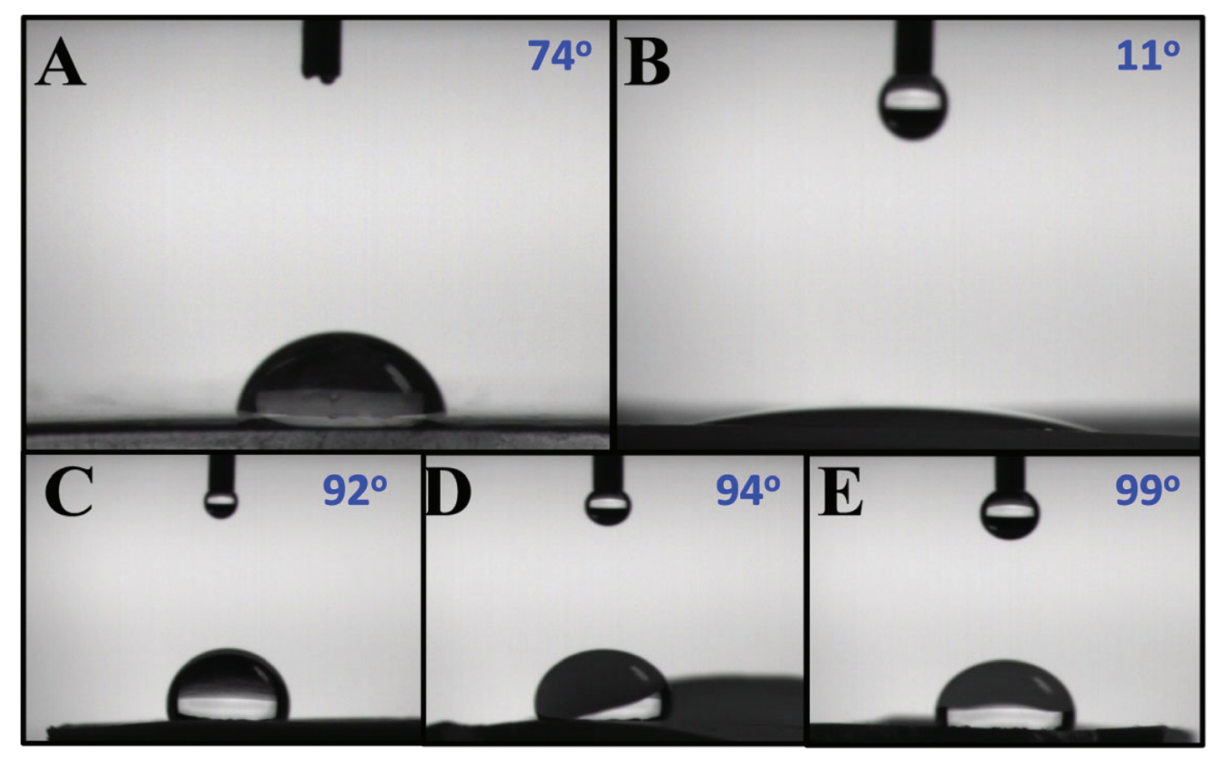

Fig. 6 Micrographs of water droplets on the surface of pristine PVC (A), POEGMA-coated PVC (B), and PPFMA-coated PVC with polymerization times of $6 \mathrm{~h}(\mathrm{C}), 12 \mathrm{~h}(\mathrm{D})$, and $24 \mathrm{~h}(\mathrm{E})$. 
order to clarify this issue, PVC sheets with and without modification with PPFMA were dissolved in THF with a concentration of $2 \mathrm{mg} \mathrm{mL}^{-1}$ and the solutions were examined by GPC using RI and UV detectors. Note that the PFMA monomer and PPFMA homopolymer are both soluble in DMSO, and the PVC sheet after polymerization of PFMA was washed with DMSO repeatedly until no phenyl signal was detected by ${ }^{1} \mathrm{H}$ NMR in DMSO eluent. An eluent peak appeared at about $17 \mathrm{~min}$ for the pristine PVC sheet using the RI detector (Fig. 7), while no peak at a similar position was detected by the UV detector with a detection wavelength of $276 \mathrm{~nm}$ (Fig. 7). On the contrary, an eluent peak at about 17 min was observed for the PVC sheet modified with PPFMA in both GPC curves using RI and UV detectors. Since the PPFMA homopolymer has a maximum absorption at $276 \mathrm{~nm}$, the above results clearly showed that PPFMA segments were covalently attached onto part of the PVC chains, not blended with the PVC sheet; otherwise no signal could be detected by the UV detector over the eluent time when the eluent peak of PVC appeared in RI detection. Thus, these observations clearly indicated that polymer brushes can be formed on the surface of PVC sheets by surface-initiated photo-mediated ATRP using $\operatorname{Ir}(\mathrm{ppy})_{3}$ as a photo-redox catalyst.

The chemical compositions of the pristine PVC sheet, PPFMA and PPEGMA brush modified PVC sheets were examined using XPS (Fig. 8). The survey spectrum of the pristine PVC sheet shows the presence of $\mathrm{C} 1 \mathrm{~s}$ and $\mathrm{Cl} 2 \mathrm{p}$ signals, consistent with the composition of common PVC. Besides, intensive signals of $\mathrm{O} 1 \mathrm{~s}, \mathrm{Ca} 2 \mathrm{p}$, and $\mathrm{S} 2 \mathrm{p}$ were also observed, possibly attributed to some additives in commercial PVC sheets. For the POEGMA-coated PVC sheet, the molar ratios of $\mathrm{C} / \mathrm{Cl}$ and $\mathrm{O} / \mathrm{Cl}$ are 11.58 and 4.45 , respectively, much higher than those of pristine PVC as shown in Table 3 (6.38 and 1.63). These distinct increases after surface-initiated photo-mediated ATRP verified the covering of POEGMA brushes. For the PPFMA-coated PVC sheet, a remarkable peak attributed to $\mathrm{F} 1 \mathrm{~s}$ appeared at $685.3 \mathrm{eV}$ and the molar ratios of $\mathrm{C} / \mathrm{Cl}$ and $\mathrm{O} / \mathrm{Cl}$ are 19.67 and 4.65, also much higher than those of pristine PVC. These results clearly proved the formation of PPFMA and POEGMA brushes on the surface of the PVC sheets.

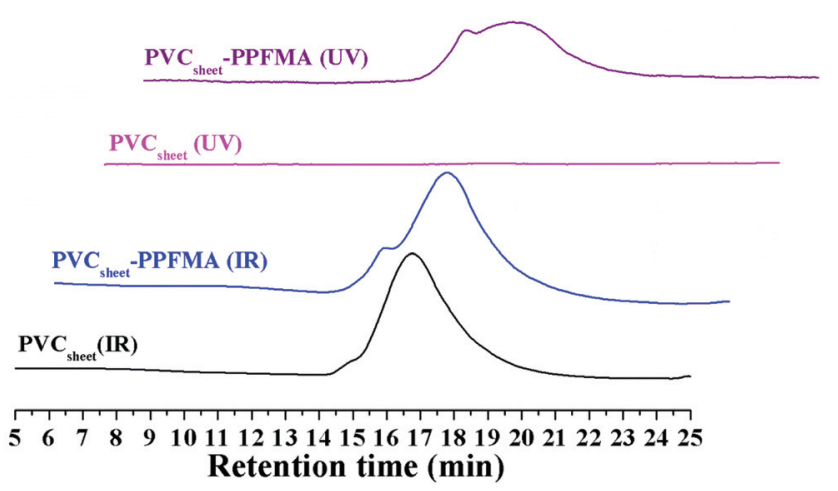

Fig. 7 GPC curves of the pristine PVC sheet and PPFMA-coated PVC sheet using RI and UV $(\lambda=276 \mathrm{~nm})$ detectors.

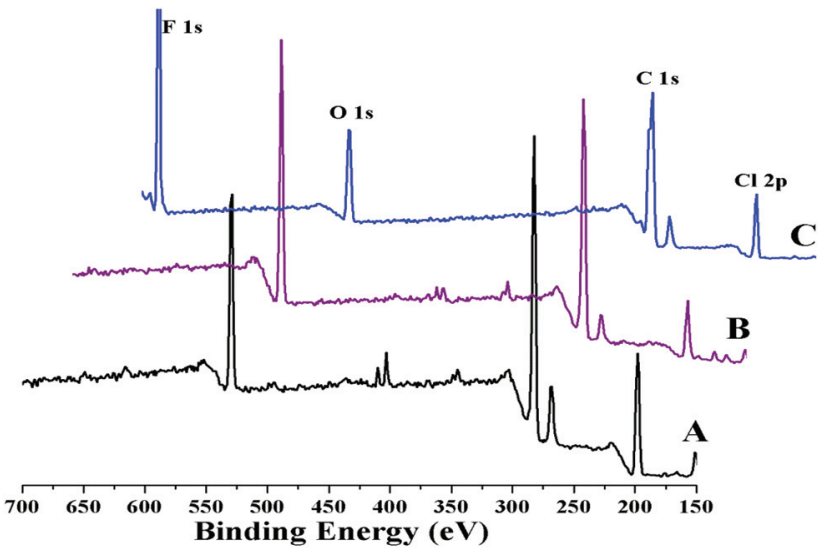

Fig. 8 XPS survey scan spectra for pristine PVC (A), PPFMA-coated PVC (B), and POEGMA-coated PVC (C).

Table 3 XPS results of pristine PVC and functionalized PVC sheets ${ }^{2}$

\begin{tabular}{|c|c|c|c|}
\hline Sample & $\mathrm{C} / \mathrm{Cl}$ & $\mathrm{F} / \mathrm{Cl}$ & $\mathrm{O} / \mathrm{Cl}$ \\
\hline PVC & 6.38 & N/A & 1.65 \\
\hline PPFMA-coated PVC ${ }^{b}$ & 19.67 & 6.15 & 4.65 \\
\hline POEGMA-coated PVC $^{b}$ & 11.58 & $\mathrm{~N} / \mathrm{A}$ & 4.45 \\
\hline
\end{tabular}

${ }^{a} \mathrm{C} / \mathrm{Cl}, \mathrm{F} / \mathrm{Cl}$, and $\mathrm{O} / \mathrm{Cl}$ ratios are determined by taking a ratio of $\mathrm{Cl} 2 \mathrm{p}$, $\mathrm{C} 1 \mathrm{~s}, \mathrm{~F} 1 \mathrm{~s}$, and $\mathrm{O} 1 \mathrm{~s}$ signals measured using XPS. ${ }^{b}$ Prepared by surface-initiated photo-mediated ATRP, polymerization time: $12 \mathrm{~h}$.

We then tested the spatially controlled capacity of the polymerization on surface modification of PVC sheets. A commercial PVC sheet with a dimension of $50 \mathrm{~mm} \times 30 \mathrm{~mm}$ without any further surface treatment was layered with a solution of PFMA $\left(0.4 \mathrm{~mol} \mathrm{~L}^{-1}\right)$ and $\operatorname{Ir}(\mathrm{ppy})_{3}\left(2.0 \times 10^{-5} \mathrm{~mol} \mathrm{~L}^{-1}\right)$ in $20 \mathrm{~mL}$ DMSO, and irradiated with blue LED light strips $(10 \mathrm{~W}$, 460-470 $\mathrm{nm}$ ) through a photo-mask, without the deoxygenation procedure, for $24 \mathrm{~h}$ as illustrated in Fig. 9A. After the sheet was washed with DMSO repeatedly until no phenyl

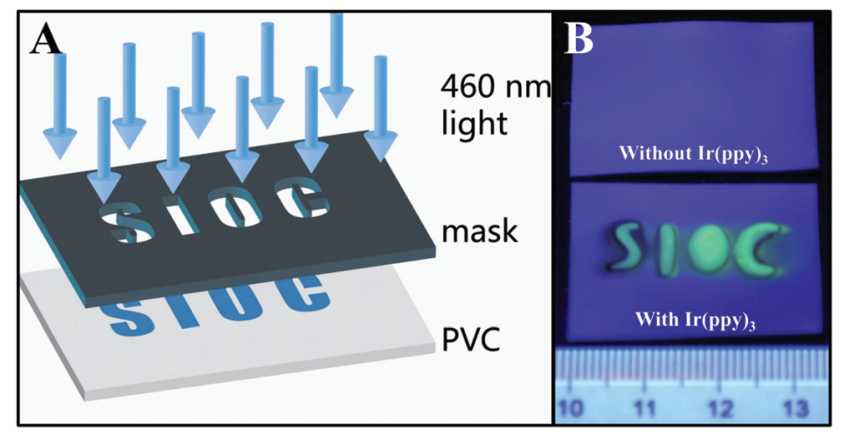

Fig. 9 (A) Schematic illustration of patterned polymer brushes on the surface of the PVC sheet and (B) optical images of the PVC sheets after polymerization with and without the addition of the $\operatorname{Ir}(\mathrm{ppy})_{3}$ photoredox catalyst. 
signal was detected by ${ }^{1} \mathrm{H}$ NMR in DMSO eluent, it was placed under UV light with a wavelength of around $265 \mathrm{~nm}$. One can clearly see "SIOC" under the UV light (Fig. 9B), which indicated that functionalization only occurred on the position of the substrate where the light reached. In order to exclude the possibility that the light itself might induce the pattern, a control experiment was performed. Another PVC sheet was immersed into a solution of PFMA $\left(0.4 \mathrm{~mol} \mathrm{~L}^{-1}\right)$ in DMSO without the addition of the $\operatorname{Ir}(\mathrm{ppy})_{3}$ photo-redox catalyst, and irradiated with a fluorescent lamp for $24 \mathrm{~h}$ through the same photo-mask. Under UV light, no pattern can be visualized in the upper image of Fig. 9B. These observations clearly demonstrated that the exposed region of the surface was functionalized with PPFMA segments by surface-initiated polymerization from PVC catalyzed with $\operatorname{Ir}(\mathrm{ppy})_{3}$ under the light. Considering the broad functionality tolerance of photomediated ATRP and the high reactivity of the pentafluorophenyl ester group toward amino and hydroxyl groups, this photoredox mediated ATRP shows great potential in the fabrication of well-defined chemically differentiated regions of the surface of commercial PVC.

\section{Conclusions}

We report a robust strategy of photo-mediated ATRP to directly modify commercially available PVC without any functional group transformation, in which the structural defects of allyl chloride and tertiary chloride groups of commercial PVC, formed during its preparation process, along with some of the secondary chlorides of VC repeated units, can be activated by an $\operatorname{Ir}(\text { ppy })_{3}$ photo-redox catalyst under irradiation with blue LED light strips $(10 \mathrm{~W}, 460-470 \mathrm{~nm})$ and serve as initiating sites for ATRP of methacrylate monomers including MMA, PFMA, and OEGMA. This approach shows great advantages over the approaches of plasma-ion beam and electric discharge treatment for the modification of PVC, as it can directly introduce functional moieties into PVC without prerequisites of special instruments for functionalization. It is also better than the conventional ATRP approach since this technique exhibited some attractive merits, such as the requirement of an ultralow concentration of photocatalyst $\left(\operatorname{Ir}(\mathrm{ppy})_{3}\right.$, ppm range) for mediating the polymerization under blue LED light with low intensity, capacity to perform without a tedious deoxygenation procedure, and compatibility with acidic monomer MAA. Furthermore, analogous with the pervasive nature of photopolymerization, this approach displays an excellent property in the spatial and temporal control over the formation of polymer brushes on the surface of PVC toward functionalization of commercial PVC sheets without a deoxygenation procedure. Given the wide application of PVC in the industrial world and our daily life and the importance of the surface properties of PVC on its performance, the distinguishing features of this strategy for the modification of PVC undoubtedly will make this technique a practical and efficient tool for the fabrication of PVC-based functional materials.

\section{Acknowledgements}

The authors thank the financial support from the National Basic Research Program of China (2012CB720300), International Science \& Technology Cooperation Program of China (2014DFE40130), National Natural Science Foundation of China (21474127 and 21504102), Shanghai Rising Star Program (14QA1404500), and Shanghai Scientific and Technological Innovation Project (13ZR1464800 and 14520720100).

\section{Notes and references}

1 D. Braun, J. Polym. Sci., Part A: Polym. Chem., 2004, 42, 578586.

2 F. Chiellini, M. Ferri, A. Morelli, L. Dipaola and G. Latini, Prog. Polym. Sci., 2013, 38, 1067-1088.

3 E. Yousif, J. Salimon and N. Salih, J. Saudi Chem. Soc., 2015, 19, 131-141.

4 S. Moulay, Prog. Polym. Sci., 2010, 35, 303-331.

5 N. Demirci, M. Demirel and N. Dilsiz, Adv. Polym. Technol., 2014, 33, 214-235.

6 N. Dumitrascu, T. Balau, M. Tasca and G. Popa, Mater. Chem. Phys., 2000, 65, 339-344.

7 D. J. Balazs, K. Triandafillu, Y. Chevolot, B. O. Aronsson, H. Harms, P. Descouts and H. J. Mathieu, Surf. Interface Anal., 2003, 35, 301-309.

8 S. Chandra, K. Sharma and A. Kumar, J. Saudi Chem. Soc., 2014, 18, 555-560.

9 M. Pawlak, E. Grygolowicz-Pawlak and E. Bakker, Anal. Chem., 2010, 82, 6887-6894.

10 J. Zhu, Y. Su, X. Zhao, Y. Li, J. Zhao, X. Fan and Z. Jiang, Ind. Eng. Chem. Res., 2014, 53, 14046-14055.

11 Z. Pi and J. P. Kennedy, J. Polym. Sci., Part A: Polym. Chem., 2001, 39, 1675-1680.

12 V. Percec and F. Asgarzadeh, J. Polym. Sci., Part A: Polym. Chem., 2001, 39, 1120-1135.

13 V. Percec, A. Cappotto and B. Barboiu, Macromol. Chem. Phys., 2002, 203, 1674-1683.

14 N. Bicak and M. Ozlem, J. Polym. Sci., Part A: Polym. Chem., 2003, 41, 3457-3462.

15 N. Bicak, B. Karagoz and D. Emre, J. Polym. Sci., Part A: Polym. Chem., 2006, 44, 1900-1907.

16 S. H. Ahn, W. S. Chi, J. T. Park, J. K. Koh, D. K. Roh and J. H. Kim, Adv. Mater., 2012, 24, 519-522.

17 J. T. Park, J. H. Prosser, S. H. Ahn, S. J. Kim, J. H. Kim and D. Lee, Adv. Funct. Mater., 2013, 23, 2193-2200.

18 D. K. Roh, S. J. Kim, H. Jeon and J. H. Kim, ACS Appl. Mater. Interfaces, 2013, 5, 6615-6621.

19 P. Liu, Y. Liu and Z. Su, Ind. Eng. Chem. Res., 2006, 45, 2255-2260.

20 Z. Guan and B. Smart, Macromolecules, 2000, 33, 6904-6906.

21 Q. Yang, F. Dumur, F. Morlet-Savary, J. Poly and J. Lalevee, Macromolecules, 2015, 48, 1972-1980.

22 S. Dadashi-Silab, M. A. Tasdelen and Y. Yagci, J. Polym. Sci., Part A: Polym. Chem., 2014, 52, 2878-2888. 
23 D. Konkolewicz, K. Schroeder, J. Buback, S. Bernhard and K. Matyjaszewski, ACS Macro Lett., 2012, 1, 1219-1223.

24 A. Anastasaki, V. Nikolaou, Q. Zhang, J. Burns, S. R. Samanta, C. Waldron, A. J. Haddleton, R. McHale, D. Fox, V. Percec, P. Wilson and D. M. Haddleton, J. Am. Chem. Soc., 2014, 136, 1141-1149.

25 A. Anastasaki, V. Nikolaou, A. Simula, J. Godfrey, M. Li, G. Nurumbetov, P. Wilson and D. M. Haddleton, Macromolecules, 2014, 47, 3852-3859.

26 B. Wenn, M. Conradi, A. D. Carreiras, D. M. Haddleton and T. Junkers, Polym. Chem., 2014, 5, 3053-3060.

27 T. Zhang, T. Chen, I. Amin and R. Jordan, Polym. Chem., 2014, 5, 4790-4796.

28 T. Gong, B. J. Adzima and C. N. Bowman, Chem. Commun., 2013, 49, 7950-7952.

29 B. P. Fors and C. J. Hawker, Angew. Chem., Int. Ed., 2012, 51, 8850-8853.

30 N. J. Treat, B. P. Fors, J. W. Kramer, M. Christianson, C. Y. Chiu, J. R. D. Alaniz and C. J. Hawker, ACS Macro Lett., 2014, 3, 580-584.

31 J. E. Poelma, B. P. Fors, G. F. Meyers, J. W. Kramer and C. J. Hawker, Angew. Chem., Int. Ed., 2013, 52, 6844-6848.

32 B. P. Fors, J. E. Poelma, M. S. Menyo, M. J. Robb, D. M. Spokoyny, J. W. Kramer, J. H. Waite and C. J. Hawker, J. Am. Chem. Soc., 2013, 135, 14106-14109.

33 M. Ciftci, M. A. Tasdelen and Y. Yagci, Polym. Chem., 2014, 5, 600-606.

34 M. Eberhardt, R. Mruk, R. Zentel and P. Theato, Eur. Polym. J., 2005, 41, 1569-1575.

35 D. A. Nicewicz and D. W. C. MacMillan, Science, 2008, 322, 77-80.

36 M. A. Ischay, M. E. Anzovino, J. Du and T. P. Yoon, J. Am. Chem. Soc., 2008, 130, 12886-12887.

37 M. R. Narayanam, J. W. Tucker and C. R. J. Stephenson, J. Am. Chem. Soc., 2009, 131, 8756-8757.

38 J. M. R. Narayanam and C. R. J. Stephenson, Chem. Soc. Rev., 2011, 40, 102-113.

39 J. T. Xu, K. Jung and C. Boyer, Macromolecules, 2014, 47, 4217-4229.

40 C. K. Prier, D. A. Rankic and D. W. C. MacMillan, Chem. Rev., 2013, 113, 5322-5363.

41 S. Thayumanavan, J. M. Zhuang, S. Jiwpanich and V. D. Deepak, ACS Macro Lett., 2012, 1, 175-179.
42 A. Das and P. Theato, Chem. Rev., 2016, 116, 1434-1495.

43 A. Das and P. Theato, Macromolecules, 2015, 48, 86958707.

44 J. Trmcic-Cvitas, E. Hasan, M. Ramstedt, X. Li, M. A. Cooper, C. Abell, W. T. S. Huck and J. E. Gautrot, Biomacromolecules, 2009, 10, 2885-2894.

45 X. Deng, N. M. B. Smeets, C. Sicard, J. Wang, J. D. Brennan, C. D. M. Filipe and T. Hoare, J. Am. Chem. Soc., 2014, 136, 12852-12855.

46 W. H. Starnes, H. Chung, B. J. Wojciechowski, D. E. Skillicorn and G. M. Benedikt, Adv. Chem. Ser., 1996, 249, 3-18.

47 V. Percec and F. Asgarzadeh, J. Polym. Sci., Part A: Polym. Chem., 2001, 39, 1120-1135.

48 A. D. Asandei and V. Percec, J. Polym. Sci., Part A: Polym. Chem., 2001, 39, 3392-3418.

49 W. H. Starnes, F. C. Schilling, I. M. Plitz, R. E. Cais, D. J. Freed, R. L. Hartless and F. A. Bovey, Macromolecules, 1983, 16, 790-807.

50 K. Matyjaszewski and R. Poli, Macromolecules, 2005, 38, 8093-8100.

51 M. B. Gillies, K. Matyjaszewski, P. O. Norrby, T. Pintauer, R. Poli and P. Richard, Macromolecules, 2003, 36, 85518559.

52 D. J. Keddie, G. Moad, E. Rizzardo and S. H. Thang, Macromolecules, 2012, 45, 5321-5342.

53 C. J. Hawker, A. W. Bosman and E. Harth, Chem. Rev., 2001, 101, 3661-3688.

54 K. Matyjaszewski, Macromolecules, 2012, 45, 4015-4039.

55 K. Min, W. Jakubowski and K. Matyjaszewski, Macromol. Rapid Commun., 2006, 27, 594-598.

56 K. Matyjaszewski, H. Dong, W. Jakubowski, J. Pietrasik and A. Kusumo, Langmuir, 2007, 23, 4528-4531.

57 C. Visnevskij and R. Makuska, Macromolecules, 2013, 46, 4764-4771.

58 B. M. Rosen and V. Percec, Chem. Rev., 2009, 109, 50695119.

59 N. Zhang, S. R. Samanta, B. M. Rosen and V. Percec, Chem. Rev., 2014, 114, 5848-5958.

60 J. T. Xu, K. Jung, A. Atme, S. Shanmugam and C. Boyer, J. Am. Chem. Soc., 2014, 136, 5508-5517.

61 S. Shanmugam, J. T. Xu and C. Boyer, Macromolecules, 2014, 47, 4930-4942. 